\title{
Environmentally Sustainable Architecture: Material-Based Technological Design Approach
}

\author{
MAZIAR ASEFI ${ }^{1 *}$ and ZAHRA AFZALI ${ }^{2}$ \\ ${ }^{1 \star}$ Associate Professor, PhD, Department of Architecture and Urbanism, \\ Tabriz Islamic Art University, Tabriz, Iran. \\ ${ }^{2}$ Master of Architectural Technology, Tabriz Islamic Art University, Tabriz, Iran.
}

http://dx.doi.org/10.12944/CWE.11.1.04

(Received: January 18, 2016; Accepted: February 07, 2016)

\begin{abstract}
This paper investigates material-based design approach in architectural forms where form generating process is informed by the combination of material properties and behavior as well as environmental constraints. It also tries to inform architects of the necessity of shift from formal form finding processes based on values of industrial age toward materiality in form generating processes. It also tries to overlook the current design practices in material-base design approaches to achieve a holistic understanding of the design process and possibilities. Through a comparative literature review, and an examination of current design practices, this paper elaborates on distinct materialbased approach to design architectural form.
\end{abstract}

Key words: Materiality, Biomimicry, Bio-inspired, Ecology, Material-based design, Sustainable.

\section{INTRODUCTION}

The ecological failure of modern design approaches to architectural design triggered the necessity of change in architectural design approaches. The emergence of bionic and sustainable approaches in architectural domain is a representative of an attempt to counteract the ecological failure of modern age. In this paper, material-based design approach is represented as a solution to the given problem and this approach is examined to point out its strength and weaknesses toward a more sustainable architecture. This paper by evaluating current and material-based approaches in the design of architectural form, is to present a new environmental design strategy. The proposed strategy, as a comprehensive design approach to architectural form is to present an effective way to achieve a more sustainable design while respecting human, environmental and functional architectural values.

\section{MATERIALS AND METHODS}

Through a comparative literature review, and an examination of material-based design approach as an architectural practice, this paper elaborates the necessity of shift from current design practices toward a more environmental-friendly design approach. The weakness of the current methods will be evaluated according to ever-changing user requirements and with respect to the environment. The available technology in terms of material and fabrication will also be taken into consideration as invaluable opportunities in the development of the proposed strategy.

The groundwork for the emergence of different architectural theories was provided since the Renaissance and especially after the advent of industrial revolution. The attention toward the use of industry in building construction led to a major shift in architectural design. The emergence 
of new materials, new construction methods, and large number of industrial products, fast increasing population and the need for rapid construction of buildings after world war all together reinforced the progress of modern architecture. Progresses in science and advent of new possibilities; architects were so impressed they separated from vernacular architectural principles and adapted new trends in design and those who were interested in vernacular architecture were mostly inspired by its formal and aesthetical aspects. These increasing developments in building industry led into separation of architectural and structural design processes as well as construction and emergence of architectural and construction companies are a testament to it. Development in building industry, computer science related to design and analysis of form and structure reinforced the tendency toward free form architecture and construction of complex geometry forms.

Over time global warming and pollution caused by modern age prompts architects toward new design strategies to counteract the effect of building construction on environment. Emerging approaches like bionic, sustainable, and green in architectural domain all expresses the necessity of change in architectural design approaches.

Despite the disadvantages of modern architecture, design processes promoted by industrial revolution and values of mass production are largely intact in which it led into separation of form, analysis and fabrication while in vernacular architecture the holistic understanding of traditional constructing materials, their structural behavior and fabrication constraints led architects into design and fabrication as an integrated process.

\section{The necessities of a new Environmental-Friendly Design approach}

Material-based design approach is developed to achieve a more sustainable design approach. In this approach the processes of form-generation are informed by the combination of material properties and environmental constraints ${ }^{1}$. Over the long trajectory of architectural design history, in contradistinction to craft in which material and form are intertwined into tradition of making while in modern design they've evolved away from this integration into separation of form making independent of its sources in material knowledge [2]. Today, due to the imperative recognition of modern design's ecological failure, design culture is witnessing a new materiality [3].

Development in technology provides new possibilities for materiality in various stages of architectural design processes. Material-based design is a new approach to design that explores the way in which material behavior and properties can be utilized at the very beginning of design processes to make resulting architecture more sustainable. Unlike current design practices of architectural form generation, material-based design seeks for the integration of design and fabrication processes inspired by nature's strategies. Nature's way of design shows that endless differentiate forms are possible through minimum resources. Figure 1 illustrates the process of design in materialbased approach in comparison with current deign practices in architecture. In current design practices, architects design forms and then send them to engineers for environmental and structural analysis and sometimes optimization and when the form is finalized, the constructional expertise start the fabrication processes. This design approach is highly inefficient as it waste a lot of resources to achieve the desired architectural form. In material-base design approach inspired by nature, form generation is driven by maximal performances with minimal resources ${ }^{1}$.

In this approach analysis and computation of material behavior and properties at the early stage of design unfolds unexpected structural and morphological properties increasing efficiency and reinforces performances. Analysis plays a critical role during the entire morphogenetic process, not only in establishing and assessing fitness criteria related the structural and environmental capacity, but also in revealing the system's material and geometric behavioral tendencies ${ }^{4}$.

Material-based design practice is characterized by the dominance of material over shape and incorporation of material properties and behavior, structural behavior and environmental constraints inform the distribution of matter to generate form while in current design practices a virtual shapedefining parameters are typically prioritized over 
physical material and fabrication constraints, which are often considered only in hindsight, following a geometric-centric design phase ${ }^{4,5}$. Recent advances in direct digital manufacturing are enabling a shift from a geometric-centric design practice ${ }^{5}$. Such approach to design is enabled by the availability of computational design, digital fabrication and additive manufacturing and also progresses in material engineering. Computing the distribution of matter as a function of structural and environmental performance, not only to control substance variation defined per a given boundary, but better still, utilizing

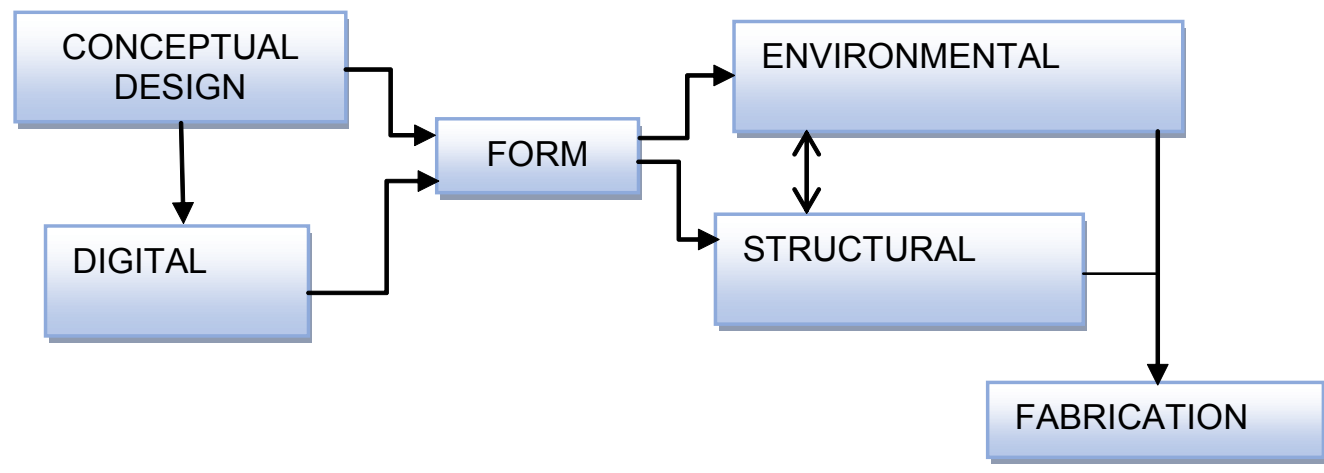

A: current design practices process

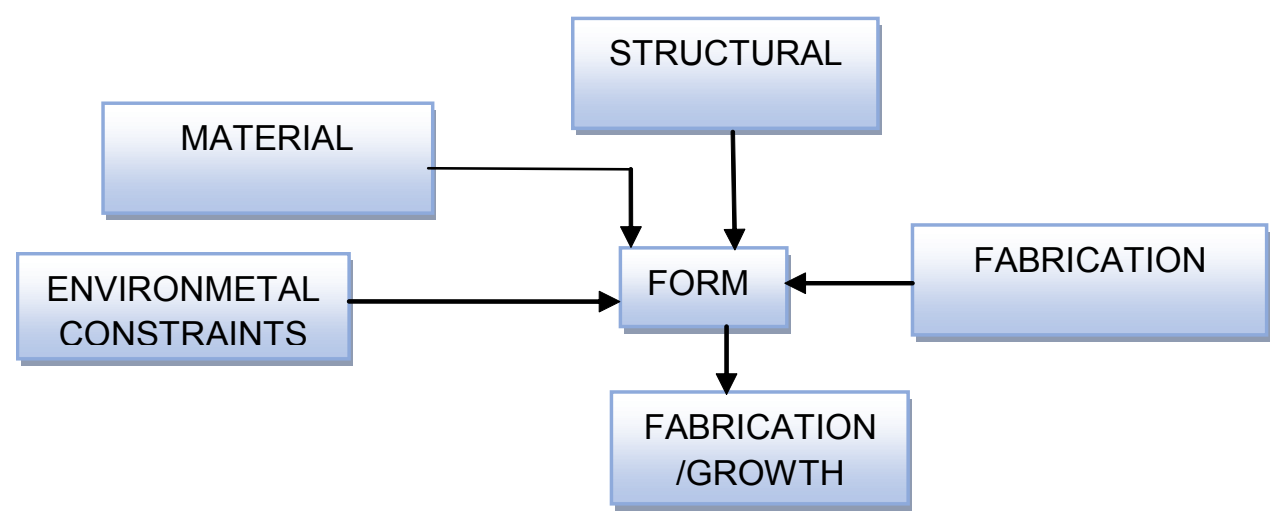

B: material-based design process

Fig. 1: Illustration of two design approach processes

Table 1: Similarities of material ecology and material morphology; material-based design approach

Similarities Of Material Ecology And Material Morphology

Form Follows Material ${ }^{6}$

Analysis Is The Initial Step Of Design Processes

Material Behavior In Micro And Macro Scale As Driving Agents Of Form Generation

Trying To Mimic Nature's Design Strategy

Integrating Design Processes Of Form

Emloying Digital Fabrication As Construction Method

The Effects Of Humane Values And Criteria On Design Are Unknown

Embracing Technology Through The Whole Process Of Design And Fabrication

Enhance The Relationship Between The Built And The Natural Environments 
such method for generation of form itself ${ }^{6}$. Material computation opens up endless form generation possibilities inspired by nature. Figure 2 illustrate main goals of material based design.

While most designers employ biomimicry as a method to increase the sustainability of what they have created ${ }^{7}$. Material-based design approach takes biomimicry to the next level where it seeks to mimic nature's way of design. Despite the potential of nature as an inspirational source to design, translation of biological knowledge to a human design setting has stayed at a shallow level since it is mostly done by mimicking form or certain mechanical aspects of organisms ${ }^{8}$. Although various forms of bio-inspired design are discussed by researchers and professionals in the field of sustainable architecture $^{9,10}$, material-based design approach is more likely to accomplish sustainability through fundamental changes in design strategies. This approach promises a true shift from conventional design methods to an approach which form generation is based on natural principles that allow it to successfully function. However the widespread and practical application of material-based design approach to design architectural form as a design method remains unrealized.

\section{Evaluation of existing material- based design strategies}

In this part, two main practices conducting research in the field of material-based design in architectural domain is examined; one by prof. Neri Oxman who conducts research at the intersection of computational design, digital fabrication, material science and synthetic biology. She uses the term material ecology to define her work.

The other one by prof. Achim Menges whose research focuses on the development of integral design processes at the intersection of morphogenetic design computation, biomimetic

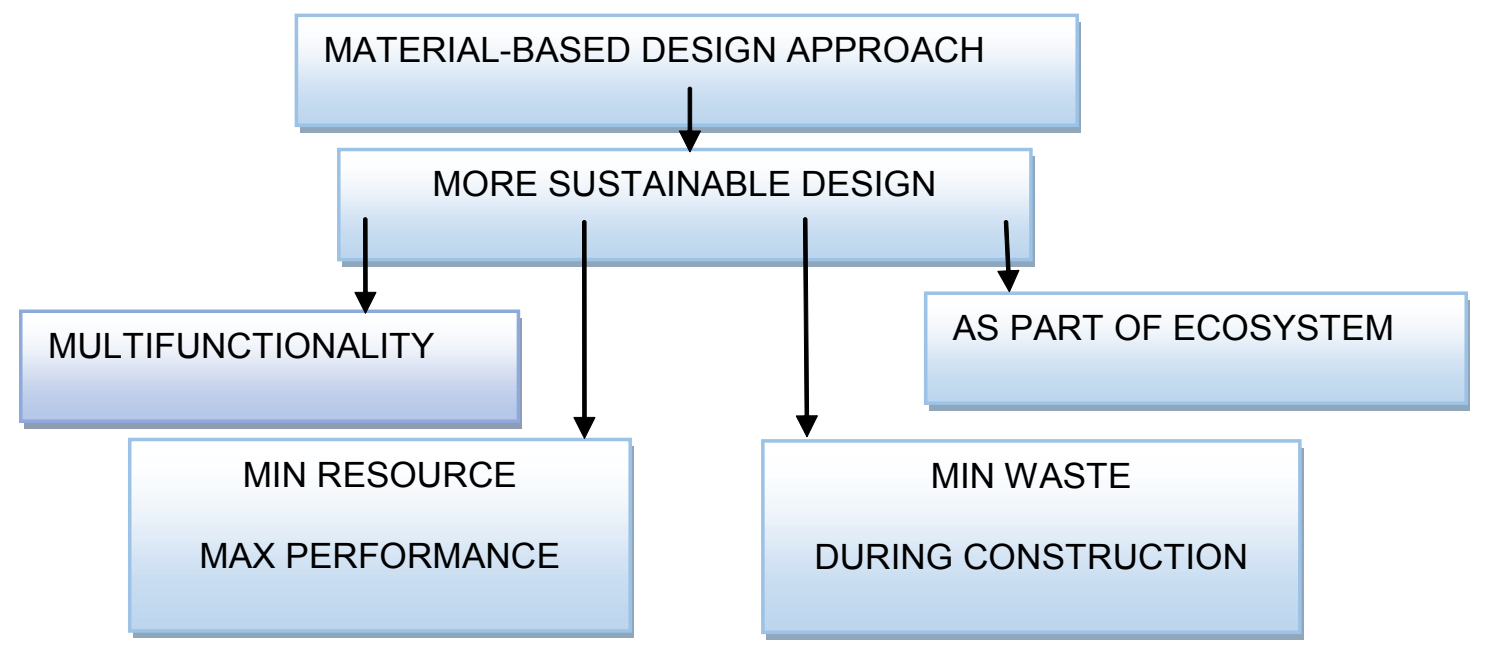

Fig. 2: Illustration of material-based design goals

Table 2: Differences in Material Ecology and Material Morphology; Material-Based Design approach

\section{Material Morphology Metrial Ecology}

Unfolds Morphological Complexity And Performative

Capacity From Material Constituents

Using Assembling Throughout Construction

Not Necessarily Multi-functional Or Seamless Designs
Create New Material Properties And Behavior

Moving Away From Assembling In Construction

Moving Toward Seemless Multi-functional

Designs Throug Anisotropic Materials 
engineering and computer aided manufacturing. His research aims to unfold morphological complexity of material constituents in design of architectural forms. In this paper his work in the field of material-based design is referred to as material morphology to be distinguished from material ecology. The comparison of these two design practices is based on the strategies that was implemented in the development of their design and research projects.

Table 1 and 2 present similarities and differences of these two design practices in the field of material-based design in architecture.Both design practices conducting by architects Oxman and Megnes seek the integration of material behavior and design computation, inspired by the principles behind nature, as active agents of form-generation. Both design practices study and compute material behavior at microscopic and macroscopic level.

Figure 3 is a great example in which Achim Megnes uses wood as responsive skin material by rediscovering new performances in wood structure by means of computational design. In this project inherent hygroscopic properties of wood as well as differentiation of wood structure in radial and tangential sections are employed to design an innate climate responsive piece of art with no need for any technical equipment or energy. This hygroscopic skin reacts to different levels of humidity and can be employed as passive solution for ventilation in building skin. This piece-of-art is being held in Centre Pompidou Paris.

Figure 4 shows Monocoque project conducted by Neri Oxman which is a structural skin

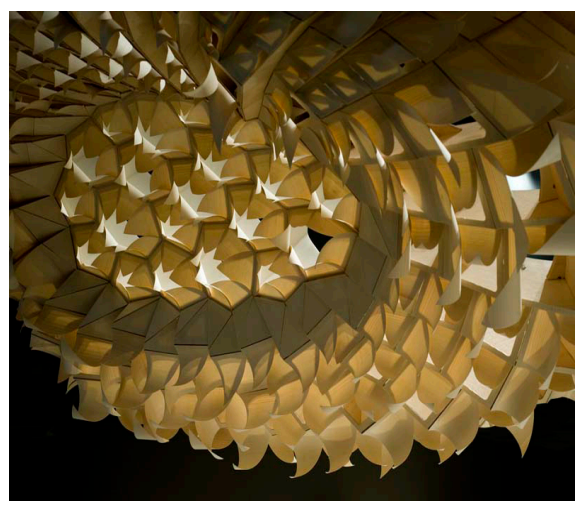

combining structural, environmental and corporeal performances by adapting its thickness, pattern density, stiffness, flexibility and translucency to load, curvature and skin pressured areas respectively ${ }^{1}$. In this project by manipulating material properties, the skin is able to achieve multi functionality. The white soft material lets light through while the black stiff material carries structural load. It should be noted that multi functionality inspired by nature is one of the main principles that prof. Oxman follows in her design projects.

Functional anisotropic material gradients on multiple length scales and locations are omnipresent in natural systems ${ }^{11}$. Prof. Oxman's desire to design heterogeneous forms into one single part in order to accomplish multi functionality and also moving away from assembly of parts by means of digital anisotropy is shown in her designs. Figure 5 shows one of Prof. Oxman projects; a large scale continuous and multidimensional structure. Its structural pattern is inspired by insect wing or leaf venation structures, and its final global shape demonstrates controlled folding into a robust and lightweight cantilever beam configuration $^{12}$. By means of additive manufacturing techniques, the varying material properties created out of carrying chemical concentration of materials was employed to generate structure that seamlessly transmitted from beam to mesh in such a large scale.

In comparison with Oxman's projects that is usually used additive manufacturing and the growth idea, Megnes mostly employs assembly in fabrication while benefiting from digital fabrication in his projects. Figure 6 shows a pavilion constructed

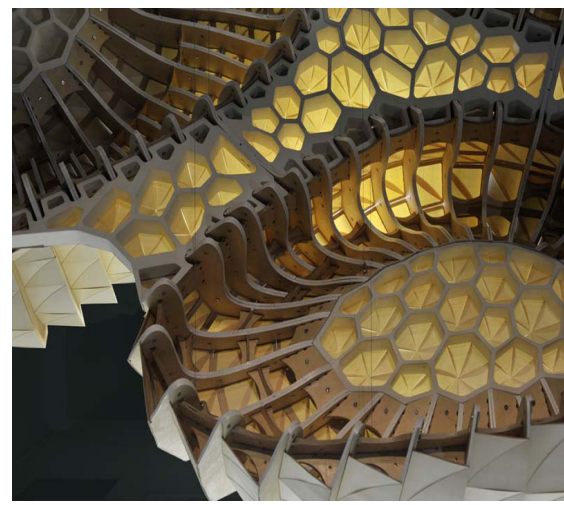

Fig. 3: Hygroscope - Metreosensitive Morphology ${ }^{15}$ 
out of simple plywood. In this project elasticity characteristic of wood is employed to compute physical complex forms. The equilibrium state of all elastic elements defines the form of the pavilion. One of the high points of this pavilion is the implementation of architectural aesthetic features integrated with material behavior and environmental constraints to achieve a highly efficient architectural form with one single material. Even though the design process was a complicate and intricate task, the result was a simple and efficient form. Integrating architectural features with material and structural behavior as well as environmental constraints as a fundamental principle in material-based design approach is an intricate and complex task that in this project is accomplish successfully. The torus shape of the pavilion as well as the light penetration through the skin of the pavilion is combined with the curved entrance of the pavilion to create an exciting architectural space.
As it is shown, prof. Oxman seeks to design forms which change not only the design processes but also fabrication processes in order to achieve forms that are highly efficient both structurally and functionally. In this approach, she also seeks to construct forms that are not fabricated but grow. Prof. Oxman's desire to a non-assembly upward toward growth in form-generation becomes apparent in the project of Silk pavilion (fig. 7). In this project digital fabrication was employed to construct the main structure of the pavilion while silk worms filled in the gaps. The process of form generation in which digital technologies and nature are employed to create a desired form is called by Prof. Oxman a design-inspired nature.

Comparing two design practices shows that materiality as a driving agent of form-generation process opens up the endless design possibilities

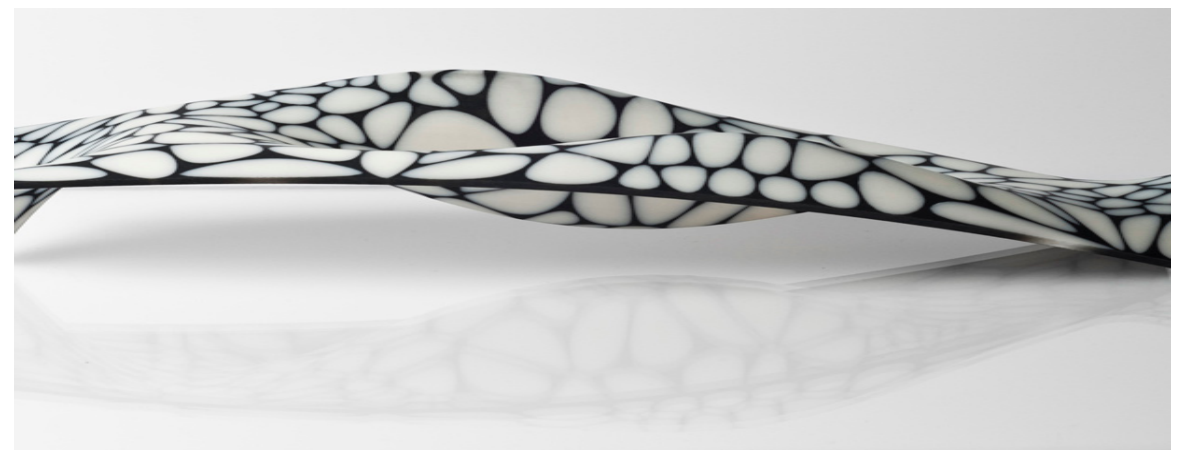

Fig. 4: Monocoque - Structural Skin ${ }^{16}$
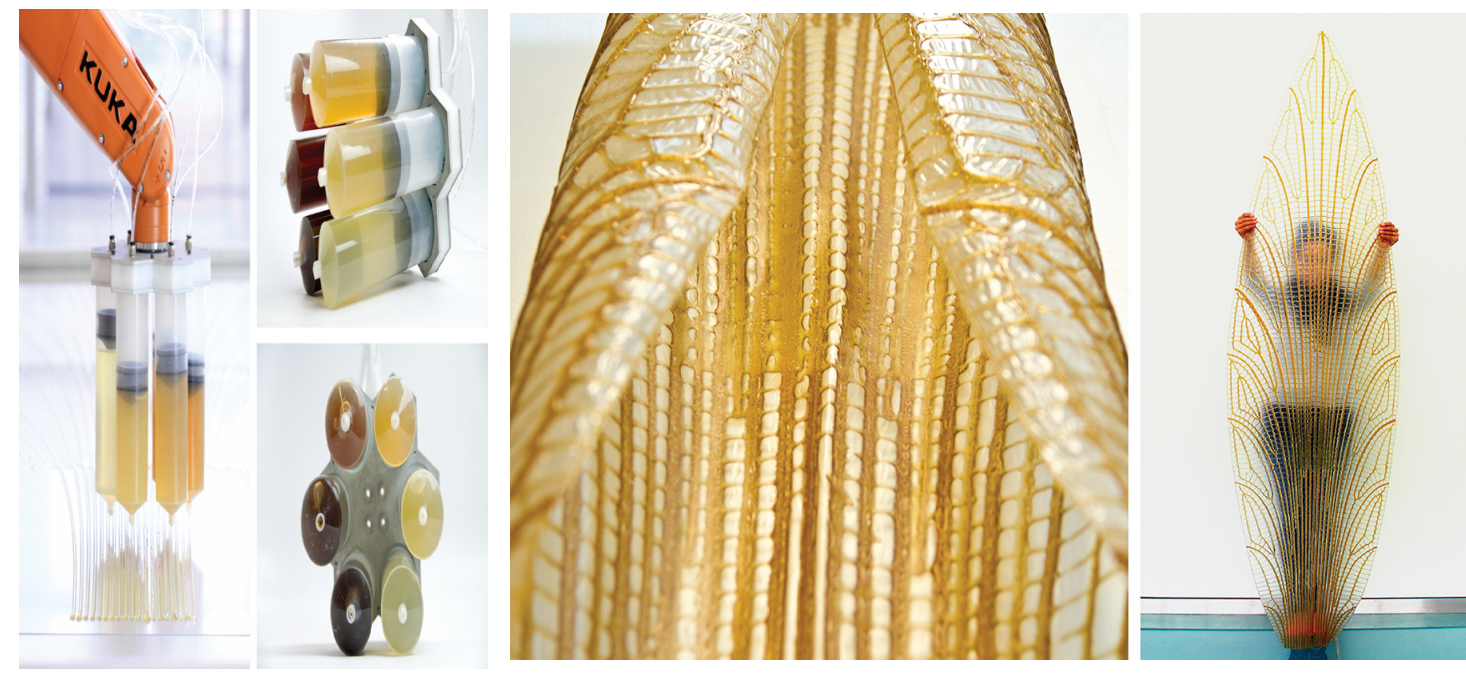

Fig. 5: hierarchically structured chitosan ${ }^{16}$ 
just like the way nature provides diverse, efficient, adaptable forms out of limited number of fibers and cells. As a whole, Megnes design practices are most likely to be followed in current architectural practices due to the similarity of forms to current architecture while much more eco-friendly. On the other hand, Oxman's design practices might lead into fundamental changes in the future of not just design processes but also the form of architectural buildings. As it is shown in previous examples of material-based design approach, diverse visionary toward form-generation as a material practice leads into different and complex design practices.

\section{The implementation of material-based design approach}

While some designers employ biomimicry as a method to increase the sustainability of what they have created $^{8}$ and as a result the outcomes witness small improvement, material-based design seeks to identify particular characteristics both in micro and macro scales through the expanding
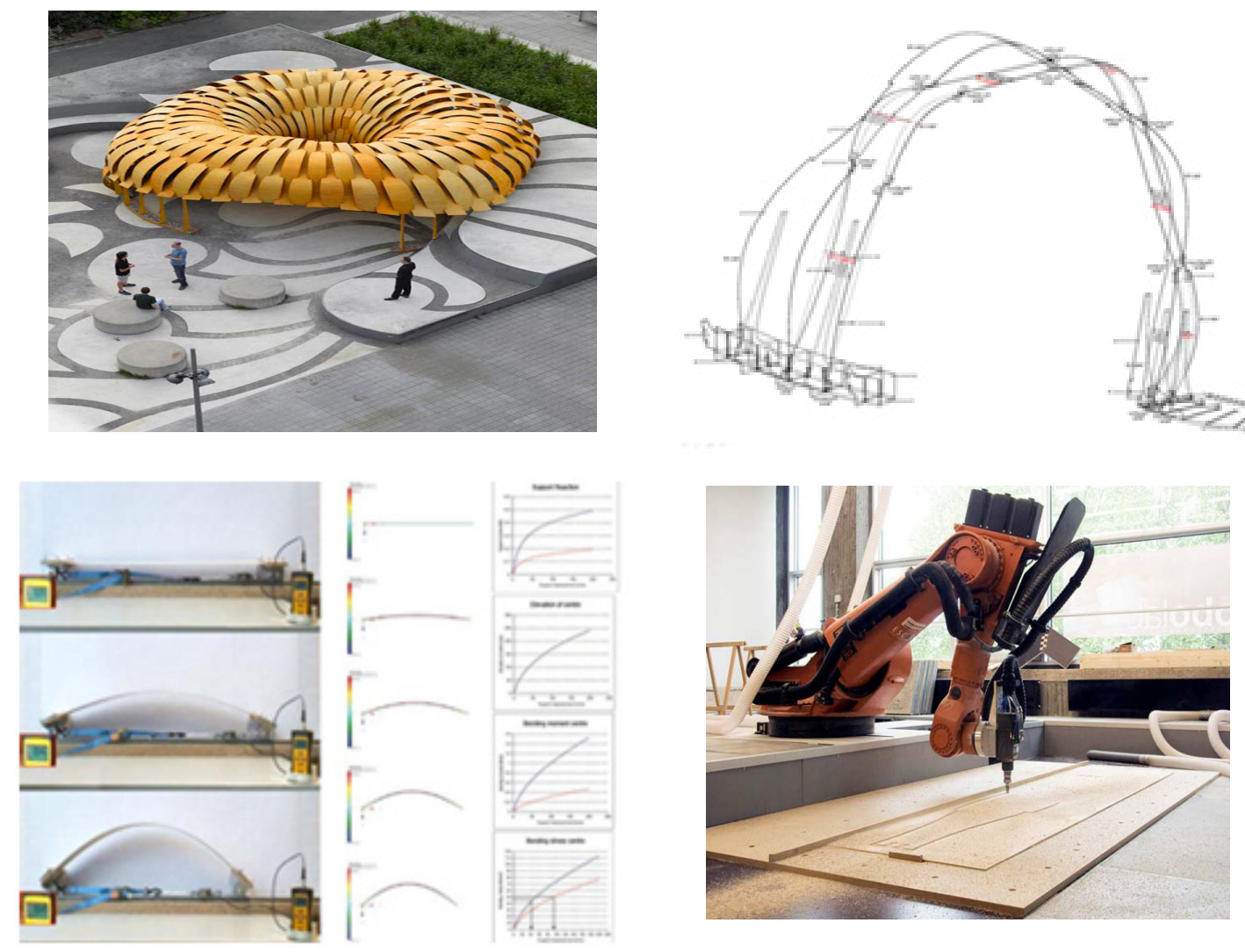

understanding of materiality in nature and translate it into a human design setting in addition to possible implication of analysis as the initial design step might lead into mimicking nature's ecosystem and not just forms and organisms. A disadvantage of this approach is that architects can't accomplish a successful design unless they have an in-depth scientific understanding and scientific collaboration through the whole design process. With limited understanding of materials, design computation and digital fabrication it is possible that the translation of such knowledge into a human design setting lead into a defective fragmentary design. On the other hand this approach can result in innovative building technologies and materials since it is possible not to just study materials but also inform materials. While other bio-inspired design approaches mainly aim to respond to particular predetermined built environment and design problems, material-based design outcome can lead into unthoughtful design solutions through studying material behavior and properties in micro and macro sale and manipulating

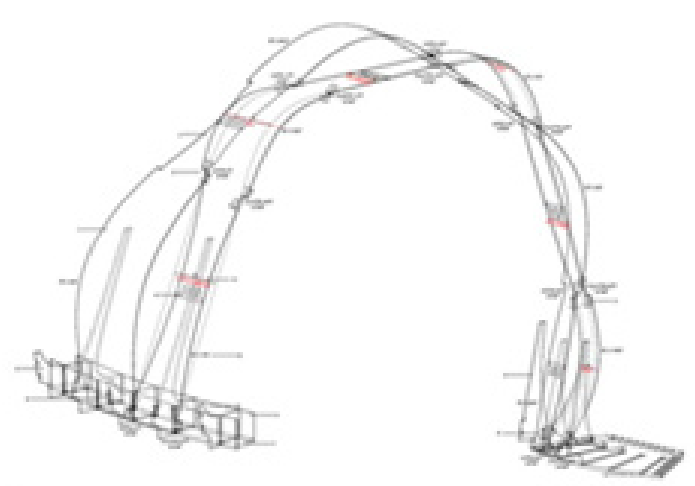

Fig. 6: Pavilion - Stuttgart University, 2010 ${ }^{15}$ 
its properties. Ecosystem mimicry could mean that an in-depth understanding of ecology drives the design of a built environment that is able to participate in the major biogeochemical material cycles of the planet (hydrological, carbon, nitrogen etc.) in a reinforcing rather than damaging way [13]. Material-based design approach can be a source for possible innovation and even a regenerative built environment. This approach can go beyond sustaining current conditions to a restorative one to nature through integration with surrounding environment and becoming part of nature's ecosystem. Actually the greatest advantage of this approach is the potential positive effect it can have on the surrounding environment and even counteracting current ecological failure of modern design. While modern design was promoted based on values of mass production, this approach is promoted based on values of sustainability raised by the ecological failure of modern architecture. Despite of modern architecture in which form follows function, in this approach form follows material behavior and properties. Material-based design approach is initially a human design setting and yet it is not known the way human values and criteria are implicated in this design process and the effects of human values on the final outcome are under investigation. Actually material-based design is seeking to attain ecological, social, cultural, aesthetical behavior at the same time so that the resulted buildings doesn't fall into the same trap of modern architecture.

It is argued that studying natural systems and the way nature designs may open a way toward strengthening architectural design strategies by considering human values while the form is generated. Studying nature's design strategies shows that each form is representative of special needs. For example body structure and behavior of Namib Desert beetles known as Fogstand beetles is a highly efficient response to the harsh arid climate of the desert as a water vapor harvesting technique ${ }^{14}$ while protecting the beetles from surrounding environment. Actually by studying
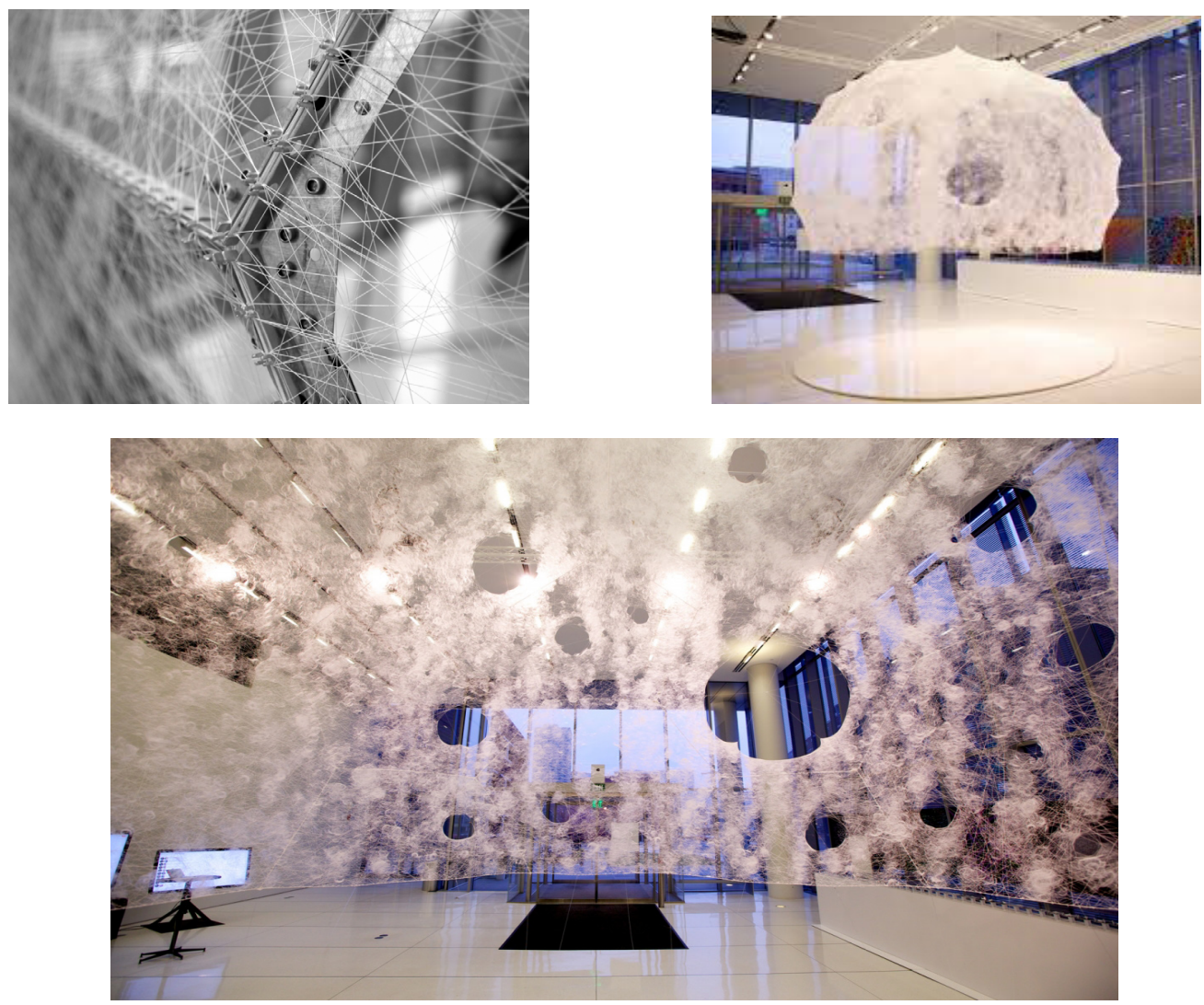

Fig. 7: Silk pavilion-2013 ${ }^{16}$ 


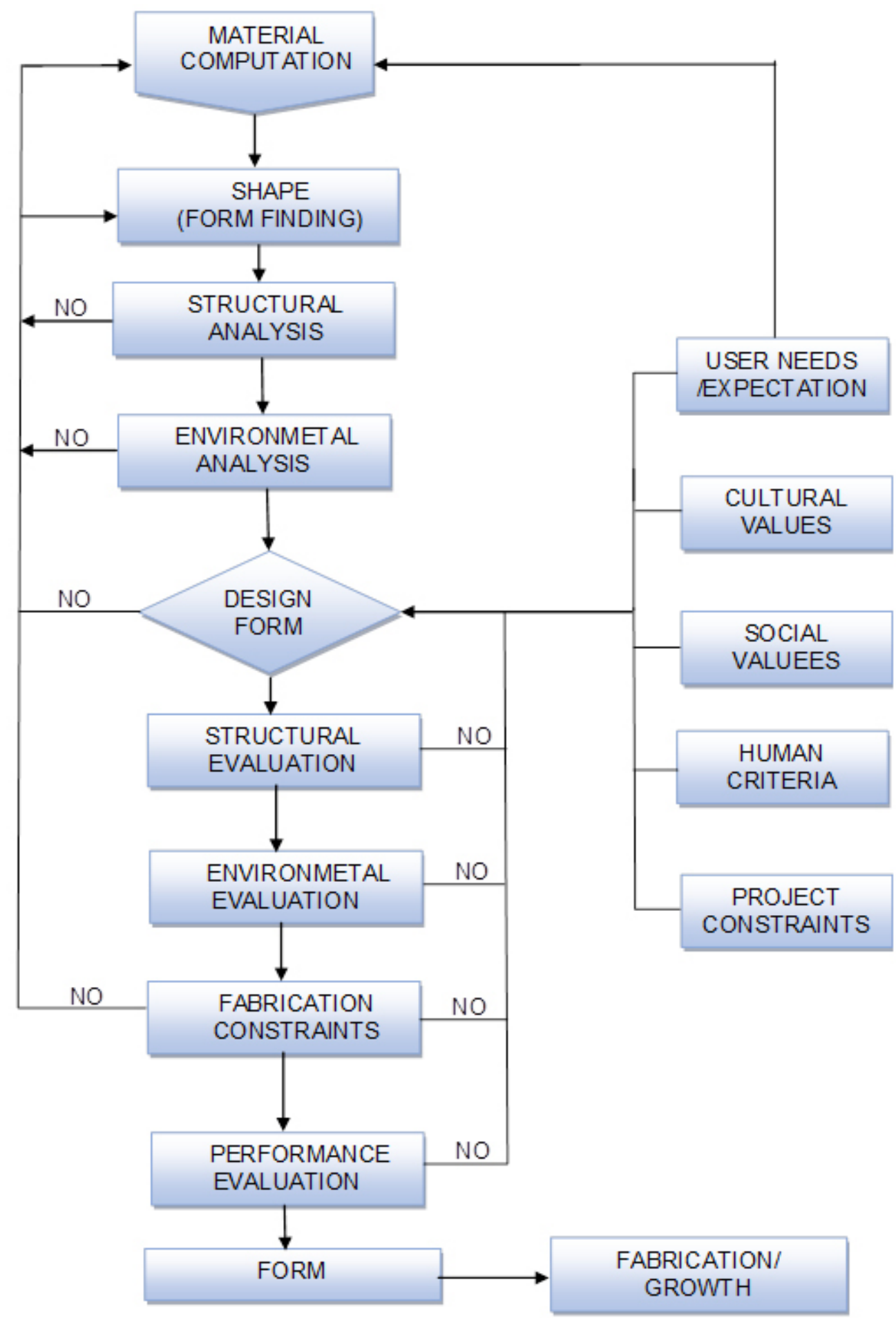

Fig. 8: Illustration of recommended design process 
nature it becomes known that different forms generated by nature are responsive to special needs and their response is highly efficient. As architecture is a response to human needs and values, therefore it is recommended to implicate human criteria in conjunctions with material and structural behavior and also environmental constraints at the early stage of design processes. This design strategy by considering both material properties and function and the form of the building in a mutual interaction is able to respond to many human and environmental needs and values while embracing technologies. It allows architect to manipulate the design not just solely based on technical, material, structural and environmental aspects but in a close connection with aesthetical, social, cultural necessities. Figure 8 shows the recommended material-based design strategy by an emphasis on how human needs and values can be implicated in the design process while achieving a sustainable architectural design. As it is also clear in the diagram in this design process it is the architect who finally guides form generation and develop it till finding an efficient response to architectural and environmental values and requirements.

\section{RESULTS}

In this approach architects are capable of designing forms that tackle many issues through careful consideration of material properties that are more efficient than other architectural design approaches in which the material characteristics are usually neglected during design development process. Material-based design approach to architectural form makes it possible for architects to generate ideas that would otherwise be impossible to solve design and construction issues in terms of environmental, material and functional requirements and ambitions.

It should be mentioned that it is hardly expected that this approach become a worldwide design approach in near future due to the fact that the form generation in this approach employs highly advanced and complicated knowledge and technologies. However, the ever-changing architectural requirements and world's environmental problems make this design strategy a necessity in the future of architectural design and construction.
Figure 8 shows the complexity of this approach by involving many parameters that are barely consider in ordinary architectural design strategies. It also shows that how this approach take into account the main three parameters of architectural design including culture, environment and society simultaneously and in a reciprocal way.

It is readily clear that it is not be possible to design and construct the whole building through material-based design approach in near future due to many undefined parameters and issues including the way different part of building such as electrical and mechanical equipment are implicated in the design. However, one should hope for implementation of this approach for the globalization of additive manufacturing in large scale and more interactive ways in the design and building fabrication. In this paper a few advantages of the application of material-based design were presented that showed how this approach can go toward a much more sustainable and eco-friendly architecture.

The proposed approach is considered as an efficient strategy for the design of kinetic architecture as it eliminates the need for joint connections and achieving the desired mechanism in a much more sufficient way and accomplishing passive design without the need to implicate external energy and technology during function time. Another great potential of material-based design approach is generating eco-resort intended building skins. Passive multi-functional building skins that make it possible for the building system to become part of the surrounding eco-system.

\section{DISCUSSION}

The ecological failure of modern architecture urges architects to seek a different route toward the ' material behavior and properties, structural and environmental behavior are the driving agents of form generation. The outcome is supposedly more efficient by achieving maximum performances through minimal resources. This approach aims to become part of eco-system and even achieving ecoresort architectural forms. Material-based design as an architectural design method is to respond to social and cultural values and many other human values and criteria, therefore it is important to define how 
these values affect final design and how the outcome can respond properly to functional, aesthetic user's requirements. As a whole, material-based design approach is the primary step toward the future sustainable architectural design practices.

\section{REFERENCES}

1. Oxman, N., Material-Based Design Computation, AD Reader, Making and Prototyping Architecture, (2012).

2. Sennet, R., The Craftsman, Yale University Press, (2008).

3. Oxman, N., Ortiz, C., Gramazio, F., Kohler, M., Material Ecology, Computer-Aided Design, Elsevier, 60: 1-2, (2014).

4. Menges, A., Computational Morphogenesis: Integral Form Generation and Materialization Processes, Em'body'ing Virtual Architecture: The Third International Conference of the Arab Society for Computer Aided Architectural Design (ASCAAD 2007), Alexandria, Egypt, pp. 725, (2007)

5. Oxman, N., Material Ecology: Uniting Principles of Engineering and Nature Sarah Wright, SPECTRUM, Massachusetts Institute of Technology, (2011).

6. Oxman, N., Material-based Design Computation. Ph.D. thesis, MIT, (2010).

7. Baumeister, D., Evolution of the Life's Principles Butterfly Diagram, personal communication, (2007).

8. Pedersen Zari, M., Biomimetic Approaches to Architectural Design for Increased Sustainability, presented at the Sustainable Building (SB07) Regional Sustainable Building Conference, Auckland, New Zealand, (2007).
9. Reed, B., Shifting our Mental Model "Sustainability" to Regeneration, Rethinking Sustainable Construction 2006: Next Generation Green Buildings, Sarasota, Florida, (2006).

10. Duro Royo, J., Mogas Soldevila, L., Oxman, N., Flow-Based Fabrication: An Integrated Computational Workflow for Design and Digital Additive Manufacturing of Multifunctional Heterogeneously Structured Objects, Elsevier , Computer-Aided Design Journal, Special Issue on Geometric and Physical Modeling for Additive Manufacturing, (2015).

11. Oxman, N., Tsai, E., Firstenberg, M., Digital Anisotropy: A Variable Elasticity Rapid Prototyping Platform, Virtual and Physical Prototyping, Volume 7, Issue 4, 2012

12. Berkebile, B., Master Speaker Address, Living Future Conference, Seattle, WA, (2007).

13. Charest, S., Ecosystem Principle Research, personal communication, May, (2007).

14. Guadarrama-Cetina, J., Mongruel, A., Medici, M.-G., Baquero, E., Parker, A.R., MilimoukMelnytchuk, I., Gonz'alez-Vĩnas, W., and Beysens, D., Dew condensation on desert beetle skin, The European Physical Journal E, 37(109), (2014).

15. Available online at: http://www.achimmenges. net

16. Available online at: matter.media.mit.edu 